\title{
THE ROLE OF MANUFACTURING STRATEGIES AND ENVIRONMENTAL HOSTILITY AS MODERATORS OF TECHNOLOGY-OVERALL PERFORMANCE RELATIONSHIP
}

SIASAT Bisist

\author{
Lena Ellitan \\ Widya Mandala Catholic University, Surabaya
}

\begin{abstract}
Technology is hardware and or software employed to solve operational problems effectively in an organization The fact that technology is a potential source of competitive advantage is widely accepted in management and economic literature. Technology adoption creates competitive opportunities and threats for those who adopt them and for those who did not. Although there have been many studies focusing on the determinants of technological adoption and innovation, there is still a dearth of empirical results that relate to technology adoption and performance, especially in the Indonesian manufacturing sector. Based on the findings of the previous studies, the increased used of advanced manufacturing technologies and new management practices cannot be directly related to higher performance, this study try to integrate technological and innovation considerations with manufacturing strategic development. This study focused on the role of manufacturing strategy and environmental hostility in moderating the impact of hard and soft technology on overall performance. The alignment between technology and manufacturing strategy is necessary to ensure success of firms. Data were collected through mailed questionnaires. Respondents were CEOs of medium and large manufacturing firms on Indonesia. The questionnaires were sent to 1000 CEOs manufacturing firms, an $18.41 \%$ response rate. Test of non-response bias indicated that the sample is representative for this study. This study finds that both hard and soft technologies have positive impacts on overall firm's performance. Further, manufacturing strategy and environmental hostility play an important moderating role on the relationship between technology and performance.
\end{abstract}

Keywords: performance, environmental hostility, manufacturing technologies

\section{INTRODUCTION}

Research on technology management and technology adoption has increased during recent years. The present concern with technology adoption is not a new one. Although there have been many studies focusing on the determinants of technological adoption and innovation, there is still a dearth of empirical results that relate to technology adoption and performance, especially in the Indonesian manufacturing sector. There is an abundant of literatures that have analyzed the relationship between technology adoption and performance (Porter, 1985; Morone, 1989; Higgins, 1995; Hottenstein \& Dean, 1995). Maidique and Patch (1988) argued that technology is a critical force for a business organization in a competitive environment. Morone (1989) viewed technology as a source of competitive advantage. While Stcey and Aston (1990) argued that technology advancement play a vital role in long term profitability, and Higgins, (1995) identified technology as a contributing factor to successful operations. 
Prior studies on technology adoption found that the increased use of advanced manufacturing technologies (AMT) and new management practices cannot be directly related to higher performance (Sweene, 1991; Kotha \& Orne, 1989; Schroeder, et al., 1995). Significant benefits can be reaped by the firms that integrate technology and innovations considerations with strategic corporate development (Shariff, 1997). Scholars have argued that strategy must be viewed as a major moderating variable and the success of business organizations depend on the ability of new technologies to support the competitive strategy. Another issue raised on the relationship between technology and competitive advantage is whether the relationship is the same in all environmental context. Relating to this issue, several prior researches have reported that the degree of competition in the business arena (Miller \& Friesen, 1982; Zahra \& Covin, 1993) has a moderating impact on technologyperformance relationship. In a hostile environment (where competition is intense), if technology is properly deployed in product, process or its value chain, it will differentiate the company from its rivals, thus gaining competitive advantage. This study was done to investigates the impact of the level of technological adoption on performance in the Indonesian manufacturing sectors. Furthermore, it investigates the moderating role of strategy and environmental hostility on the technology-overall performance relationship.

\section{LITERATURE REVIEV}

\section{Technology and Competitive Advantage}

In the globalization era, technology is perceived as an important tool for development and it appears to play a dominant role in helping the companies to achieve competitive advantage. The basic approach to define technology is to derive the concept from classical Greek. In classical Greek, the word 'technology' is the combination of 'techne' and 'logos'. The word 'techne' is interpreted as skill of hand or technique. The word 'logos' is interpreted as knowledge or science of skills or techniques (Autiou \& Leimanen, 1995). Zeleny (1986) highlighted that technology consists of three interdependent, codetermining, and equally important components: (1) hardware, which is the physical structure and logical layout of the equipment or machinery, used to carry out the required task; (2) software, which is the knowledge of how to use the hardware in order to carry out the required tasks; and (3) brainware, which is the reason for using the technology in a particular way (this may be referred to as know-why). In addition to these three, a fourth component must be considered interdependently for it encompasses all levels of technological achievement namely know-how (Khalil, 2000). Know-how is the learned knowledge or acquired knowledge of technical skill regarding how to do a thing well. This may be the result of experience, transfer of knowledge or hands-on practices.

The distinction between technological and scientific knowledge is that scientific knowledge can be articulated or verbalized, whereas, technological knowledge 
nearly always comprises of tacit component. Technological knowledge is seldom completely expressed in exact norms and theories (Autio, 1991). Furthermore, Autio asserted that technology comprises of a strong knowledge component, which can be viewed as social, so that the technological knowledge component can be transferred through social interactions. This aspect makes it necessary to combine the component approach and the social approach in defining technology. Therefore, technology can be defined as the ability to recognize technical problem, the concept and the tangible things (machines and equipment), which are developed to solve a technical problem. On the other hand, technology is hardware and software employed to solve operational problems effectively in an organization (Autio \& Leimanen, 1995).

The theory that can explains why technology adoption improves organizational performance and creates competitive advantage can be attributed to Barney (1991) and early researchers who argue for the resource-based theory of competitive advantage. The theory holds that the firm's resources are key determinants of performance and competitive advantage. Firms can develop this competitive advantage only by creating value in a way that is difficult for a competitor to imitate. In this context, hard technology is considered as a resource. On the other hand, soft technology (organizational practices) reflects capabilities of the firms, that can be used as the basis for competitive advantage.

The fact that technology is a potential source of competitive advantage is widely accepted in management and economic literature. Technological adoption and technological innovation are powerful forces for industrialization, increasing productivity, supporting growth and improving the standard of living (Abernathy \& Clark, 1985). Technological strength has affected manufacturing cost and other competitive drivers (Harrison \& Samson, 1997). Schroeder (1990) found that technology adoption creates competitive opportunities and threats for those who adopt them and for those who did not. To develop a competitive advantage, organization need to choose, design, and implement manufacturing technologies that are consistent with the needs of competitive advantage (Hottenstein \& Dean, 1995).

\section{Technology and Performance}

Numerous studies (such as Youseff, 1993; Mechling et al., 1995; and Mc Gregor \& Gomes, 1999) have emphasized the potential strategic benefit of flexible responsiveness and improved productivity through purposeful adoption of advanced manufacturing technology (AMT). Skinner (1985) argued that AMT has and will continue to play a key strategic role in improving competitiveness by utilizing the manufacturing function more effectively in the overall business strategy. Youseff (1993) found that the adoption of AMT increases efficiency (related to cost) and effectiveness (related to volume) of the firms in producing goods and services. Moreover, Zammuto and O'Connor (1992) found that AMT is more likely to provide productivity improvement rather than gains in flexibility. 
There are also numerous articles and empirical studies that investigated the impact of soft technology (e.g. TQM, JIT, TPM, MRP and benchmarking) on a firm's performance. Sohal and Terziovky (2000) argued that the effective implementation of quality improvement practices (TQM, benchmarking, process reengineering) lead to improvements in organizational performance in terms of both productivity and profitability, along with improved customer satisfaction. Ghobadian and Galear (1996) provide evidence that the adoption of TQM helps small and medium companies to improve long-term survive and growth.

Research has shown that JIT practices provide several potential benefits. First, JIT tends to eliminate waste in production process and material. Second, JIT has the potential to reduce lead-time, decrease throughput time, improve product quality, increase productivity and enhance customer responsiveness (Yasin et al., 1997). Similarly, a study by Kee (2000) amogst Malaysian SMEs found that JIT implementation plays an important role in improving operation performance such as inventory reduction, lead time reduction, increase efficiency and increased worker's morale. Sakakibara et al. (1997) found that JIT practices (set up time reduction, schedule flexibility, maintenance, equipment layout, and JIT supplier relationship) increase manufacturing performance, which in turn creates competitive advantage for the firms. Further, they explained that infrastructure alone is not sufficient to increase manufacturing performance without JIT practices.

Adoption and implementation of TPM help increase the productivity of plant and equipment in order to achieve maximum productivity (Al-Hassan et al., 2001). A study about TPM practices in Malaysia by Seng (2002) showed that the greater extent of TPM practices in an organization would bring higher performance in term of reduced product defect, better quality, and increase cost efficiency. Adoption of TPM is a contributing factor to reduce work in process (WIP), improving response to customer through reduced cycle time and improved product quality (Tsang \& Chan, 2000). TPM brings the maintenance function into focus as a necessary and important part of firms which aim to increase their performance (Yamashima, 2000).

Humpreys (2001) showed that the adoption of MRP2 can enhance firms competitive positions through improved customer service level, increased plan efficiency and more efficient production scheduling. When MRP was implemented with JIT, it reduced cost, increased productivity and integrated all functions to manufacturing (Lowe \& Sim, 1993). Benchmarking has also proven to be a common tool for enhancing organization performance (Hinton, 2000). It can be used to transfer the best practices and continuous learning to the other functions or organizations (Zairi \& Whymark, 2000)

Boumount and Schroeder (1997) suggested that achieving competitive cost and quality may not be possible without some sophisticated technologies and modern management practices. They found that although sophisticated technologies, JIT and TQM are not strongly associated with cost reduction and dependability, these technologies give benefits in terms of increasing flexibility (reduction in new product 
development time) and increasing employees' morale. Sim (2001) investigated the impact of TQM, JIT, and AMT on performance. Successive incremental improvement could streamline the production process through the elimination of non-value added activities. On the other hand, capital investment in advanced manufacturing technology is often associated with a 'quantum leap' in performance. The above literatures indicated that neglecting improvement techniques and management systems (soft technology) may result in companies not getting a pay off from investment in technology.

\section{Technology-Manufacturing Strategy Relationship}

Manufacturing strategy is viewed as the effective use of manufacturing strengths as a competitive weapon for the achievement of business and corporate goals (Swamidass and Newell, 1987). In addition, manufacturing strategy reflects the goal and strategy of business and enables the manufacturing function to contribute to the long-term competitiveness and performance of the business (Wheelwright and Hayes, 1985). Of late, manufacturing strategies adopted by manufacturing enterprises includes low cost strategy, quality strategy, flexibility strategy and dependability strategy. A manufacturing strategy is referred to by many researchers as a competitive priority (Burgess et al., 1998). Stonebaker and Leong (1994) defined a cost strategy as the production and distribution of a product with minimum expenses and wasted resources. Quality strategy focuses on the need to manufacture products and services that conform to the specifications and customer needs (Braglia, et al., 2000). Flexibility strategy is the ability to respond to the rapid changes of the products, services and processes. This strategy is often identified as a mix or volume flexibility. Leong, et al. (1989) delivery strategy as dependability of delivery (by meeting delivery schedule or promises) and speed of delivery (react quickly to customer order).

The literature on the link between technology and manufacturing strategy has been in existence for a long time (Skinner, 1974; Buffa, 1984; Burgess, et al., 1998; Cagliano \& Spigna, 2000). Skinner (1974) advocated a wide variety of strategic priorities, including low costs, product quality, delivery reliability, short delivery cycle, flexibility to produce new product quickly, and flexibility to respond to volume change. These can be achieved by using manufacturing technologies. Buffa (1984) argued that Japanese firms have gained the lead in many industries through closer attention to integrated manufacturing strategies with appropriate technologies. Burgess et al. (1998) suggested that firms need to take action to improve process performance through the adoption of process innovation. Cagliano and Spina (2000) explored the empirical basis of the strategic alignment of manufacturing strategy choices in accordance with the strategic priority and past experience in determining the selections of manufacturing improvement program. A complete strategic alignment is expected when the choice of the improvement programs is highly coherent with competitive priorities and the past experiences, thus the maximum pay-off could be achieved.

Although a number of studies have tried to investigate the technologymanufacturing strategy relationship, no clear pattern of the relationship between 
technology and its strategy has been found. Prior studies on the link between technology and manufacturing strategy tends to use the process approach which describes what technology should be adopted by companies having certain manufacturing strategies or competitive priorities. However, the way technology should align with manufacturing strategy remains unresolved. The above review of the literatures show the need to explore in greater depth the fit between manufacturing strategy and technology.

\section{Technology-Environmental Hostility-Performance Relationship}

Hostility of environment concerns with the degree of competition in the local and international market (Badri et al., 2000). The degree of hostility is measured on various dimensions e.g. degree of competition in local market and foreign market, rate of demand in local and foreign market and the changing customer's taste. Miller (1987) defined hostility as the degree of competition, number of areas of competition such as product feature, quality and service and restrictive legislation. In a hostile business environment, technology is needed to survive and create competitive advantage (Zahra \& Covin, 1993). To achieve this objective companies have to develop technology policies that are consistent or that 'fit' into the business strategy. In a hostile environment (where competition is intense), if technology is properly deployed in product, process or its value chain, it will differentiate the company from its rivals, thus gaining competitive advantage. A hostile environment will also open the windows of opportunities to exploit technology for greater returns to the more innovative and risk taker firms. In hostile environment, firms with high technology competencies and capabilities will be able to overcome the pressures and threats. These firms will successfully differentiate themselves and perform better than its competitors, thus gaining competitive advantage.

\section{Research Framework and Hypothesis}

Based on the above discussion, the theoretical framework for this research is diagrammed below.

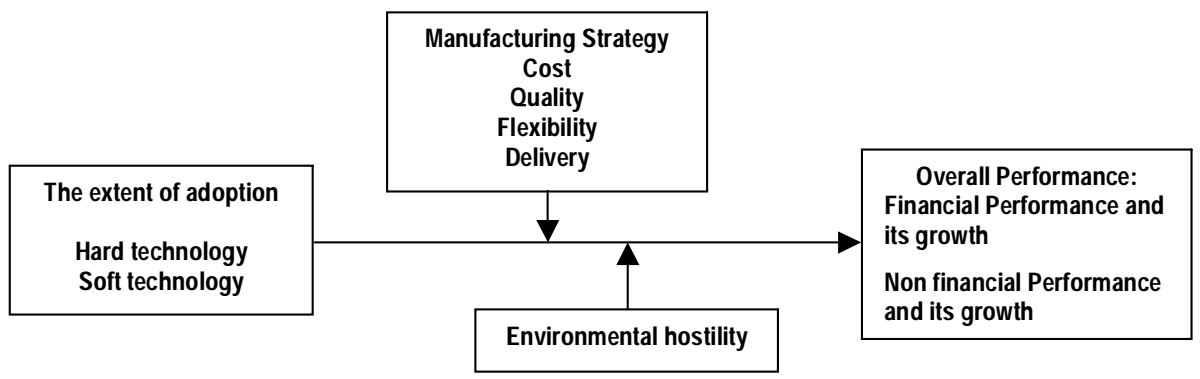

Figure 1: Research Framework 
Within this framework two major hypotheses are proposed:

H1: There is a positive impact of level of technological adoption on firms' overall performance.

H2: The impact of technology on firms' overall performance is moderated by manufacturing strategy.

H3: The impact of technology on performance is greater in a more hostile environment.

\section{RESEARCH METHOD}

\section{Sample and Response Rate}

For this study, a list of medium and large companies was obtained from the Directory of Manufacturing Industry, published by the Indonesian Statistic Center Bureau (Biro Pusat Statistic Indonesia, 2000). Data was collected through mailed questionnaires, which were addressed to the CEOs of medium and large manufacturing companies in Indonesia. The unit of analysis is organization and the sample were selected randomly from the directory. The sample selected were the manufacturing firms with more than 250 full time employees.

A total of 1000 questionnaires were sent to CEOs of large Indonesian manufacturing companies. Six companies were dropped from the target sample because four companies have moved to unknown addresses and the other two companies refused to participate. In addition, 47 incomplete responses cannot be used for this study. Finally, a total of 183 responses collected were used for the purpose of this study, an $18.41 \%$ response rate.

\section{Respondents' Profile}

The profile of the sample revealed an interesting spread of Indonesian large companies. Majority (60\%) of the responding firms have less than 1000 full time employees with only $11.5 \%$ are very large, having in excess of 2500 full time employees. It is not surprising that about $90 \%$ of them have assets in excess of 25 million Rupiahs (1 USD equal to 9.850 Rupiahs). Most of them (80\%) have been in existence for more than 10 years with only 8 companies (4.4\%) being relatively new. Twenty-eight point four percent $(28.4 \%)$ of the companies are in fabricated metal, machinery and automotive, and electronic industry, while $19.1 \%$ in food, beverage, and tobacco industry. The smallest (14.8\%) group came from rattan, bamboo, furniture, and handicraft industries. In term of ownership, approximately $87 \%$ are Indonesian owned, while the remainders are either joint venture companies or totally foreign owned. However, locally owned companies do have some degree of alliances, only $47 \%$ indicated that they do not have any cooperative arrangement with foreign entities. 


\section{Variables and Measures}

The variables of this study were measured using instruments derived from various sources.

Level of technological adoption. The two dimensions include hard technology and soft technology. Hard technology refers to a family of advanced manufacturing technologies and computer based technologies, which include 13 types of hard technology. Five point Likert type scales ( $1=$ not adopted to $5=$ very high) are used and in order to measure the level of adoption of hard technology, an instrument developed by Youseff (1993).

The level of sophistication, cost and complexity of the various hard technology varies. Thus to equate the one technology with another in coming up with a measure of extent of adoption of hard technology is inappropriate. For this study, we adopted the methodology used by Jantan, et al. (2001), where the extent of adoption is measured using the following formula:

$$
\text { The extent of hard technology (AMT) adoption }=\frac{\sum \mathrm{i}_{\mathrm{j}} \times \mathrm{w}_{\mathrm{j}}}{\sum \mathrm{w}_{\mathrm{j}}}
$$

Where:

$\mathrm{i}_{j}=$ Level of hard technology, where the value of $\mathrm{i}_{j}$ become 1 if the hard technology is not adopted at all and 5 if the hard technology is adopted at very high level.

$w_{j}=$ The importance (radicalness) index that was obtained from a panel expert. Where, $w_{j}$ become 1 if the hard technology is considered very unimportant and 5 if the hard technology is considered very important.

To establish the degree of radicalness or importance of hard technology, a separate questionnaire was prepared and sent to experts (technical or production managers) from large manufacturing companies. These managers have had experience in working with hard technology system. They are also considered as experts, and knowledgeable of the benefits of each type of hard technology and the difficulty in implementing the systems. The purpose of this part of the study is to determine the weights attached to each type of hard technology, in measuring the sophistication or extent of adoption of hard technology by the responding firms.

Soft technology refers to the system, which control the technical processes within the organization such as TQM, JIT, TPM, MRP2, and Benchmarking. TQM measure are obtained and modified from Sohal and Terziovsky (2000). For the level of JIT adoption the components from Yasin, et al. (1997) as well as Sakakibara, et al. (1997) were adopted and modified based on the objective of this study. The level of MRP2 and TPM adoption is measured with the instrument developed by Warnock (1996) and Tsang and Chan (2000), respectively. While the level of benchmarking adoption is measured based on the general benchmarking practices (Hinton, Francis, 
Holloway, 2000). A five-point Likert scale anchored by 1 (not practiced) to 5 (very high) is used to measure the level of soft technology adoption.

Manufacturing Strategy. Manufacturing strategy is defined as key decisions about the specific role to be played by manufacturing function in achieving competitive advantage (Dangayah and Deskmush, 2000), which includes cost, quality, flexibility, and delivery strategy. The instrument to measure manufacturing strategy is adopted from Badri, et al. (2000). Here, the respondents are asked to indicate their assessment to statements on five point Likert's scale ( $1=$ very unimportant to 5 = very important).

Environmental hostility. It is related to pressure and degree of competition in the market place (Friesen and Miller, 1983). It is measured by six items that were derived from Miller, (1987) and Badri et al. (2000). These items measured the degree of competition in local market and foreign market, demand in local market and foreign market and quality demand by customers.

Performance. This study looks at performance from the perspective of overall performance by comparing each firm overall performance to the average in the industry. Overall performance covers financial performance and its growth as well as manufacturing performance and its growth.

These measures were subject to factor analyses to identify the structure of interrelationship (correlation) among a large number of variables (questionnaire responses in our case) by defining common underlying dimensions, known as factors. Factor analyses were conducted on the 13 questions of hard technology, 32 questions of soft technology, and 17 questions of manufacturing strategy. The factor analysis was conducted separately for extent of advanced manufacturing technologies and 32 organizational practices, two factors come up and named as hard technology (factor 1, Cronbach's alpha .9496) and soft technology (factor 2, Cronbach' alpha .9026). The results of factor analysis for manufacturing strategies emerged with four factors, the four factors are named accordingly, delivery strategy (factor 1, Cronbach's alpha .8813), quality strategy (factor 2, Cronbach's alpha .8344), flexibility strategy., and cost strategy. High Cronbach's alpha values of each of the derived factors indicated acceptable reliability level for further analyses (Nunnaly, 1978).

\section{FINDING AND DICUSSION}

\section{The Impact of Technology on Performance}

Table 1 presents the results of multiple regression analyses, which analyzed the impact of technology on firms' overall performance. Regarding the impact of technology on overall performance we find that hard and soft technology have positive significant effects on overall performance. This finding indicates that companies can improve overall performance by adopting hard and soft technology. Adoption of hard technology is a vehicle to increase process and product quality, process and volume flexibility, as well as delivery reliability, thus improvement of manufacturing 
performance and its growth can be attained. This finding is in line with a large number of previous studies done by Youseff (1993), Baumounth \& Schroeder (1997), Buthcher et. al (1999), Gordon and Sohal (2001).

This finding also shows that the effective implementation of soft technology leads to improvement in firm's overall performance. Implementation of this technology can reduce rework, scrap, and product defect. Soft technology also plays an important role in shortening process/product development time, and enhancing delivery capability, which lead to financial performance. This study appears in line with many previous studies about adoption of soft technology (Sohal \& Terziovsky, 2000; Sakakibara, et al. 1997; Tsang and Chan, 2000; Hinton, et al. 2000). It shows that adoption of all types of soft technology will result in better performance than adoption of the specific technology. This is due complementary effect of all types of soft technology.

We also find that the impact of soft technology is greater than hard technology. Adoption of soft technology will give more benefits than hard technology. This is largely due to some factors that inhibit adoption and implementation of hard technology such as disruption during implementation, lack of integration of AMT with operation systems, skill deficiency, technical difficulties etc. These difficulties cause the impact of hard technology on manufacturing performance to be lower than that of soft technology.

Table 1: The Impact of technology on Performance

\begin{tabular}{|c|c|}
\hline Independent Variables & Manufacturing Performance \\
\hline $\begin{array}{ll} \\
\end{array}$ & .364 \\
\hline Adjusted R2 & .357 \\
\hline Sig. $\mathrm{F}$ & .000 \\
\hline Standardized Coefficients & \\
\hline Hard Technology (HT) & $.243^{\star \star \star}$ \\
\hline Soft technology (ST) & $.431^{\star \star \star}$ \\
\hline
\end{tabular}

The Moderating Impact Of Manufacturing Strategy

Hierarchical regression analysis is used to analyze the moderating impact of manufacturing strategy on the relationship between technology and performance.

\section{Cost strategy As The Moderator}

Table 2 shows the moderating role of cost strategy on the relationship between technology and overall performance. The addition of cost strategy and the interaction terms change the $\mathrm{R}^{2}$ from $38.9 \%$ to $42.6 \%$. The $\mathrm{R}^{2}$ change significantly increases and the F-change is significant at 01 level. Similarly, the significant standardized beta is found only in the interaction between soft technology and cost strategy.

Graph 1 shows the impact of cost strategy on the relationship between soft technology and the overall performance. In general, soft technology positively influ- 
ences overall performance, but the impact of soft technology seems to be greater for the companies that emphasize less cost strategy. This is because amongst companies that practice cost strategy, investment in hard or soft technology is not a priority, as this will only increase cost of operations. Therefore, amongst firms that are willing to spend on technology, the impact of technology on performance will be the same irrespective of emphasis cost strategy. The finding is in line with that Tan et al. (2000), who found that a strategy based on low cost correlates negatively with the use of product and process technology as a vehicle for performance improvement.

Table 2: The Moderating Effect of Cost Strategy on The Relationship Between Technology and Overall Performance

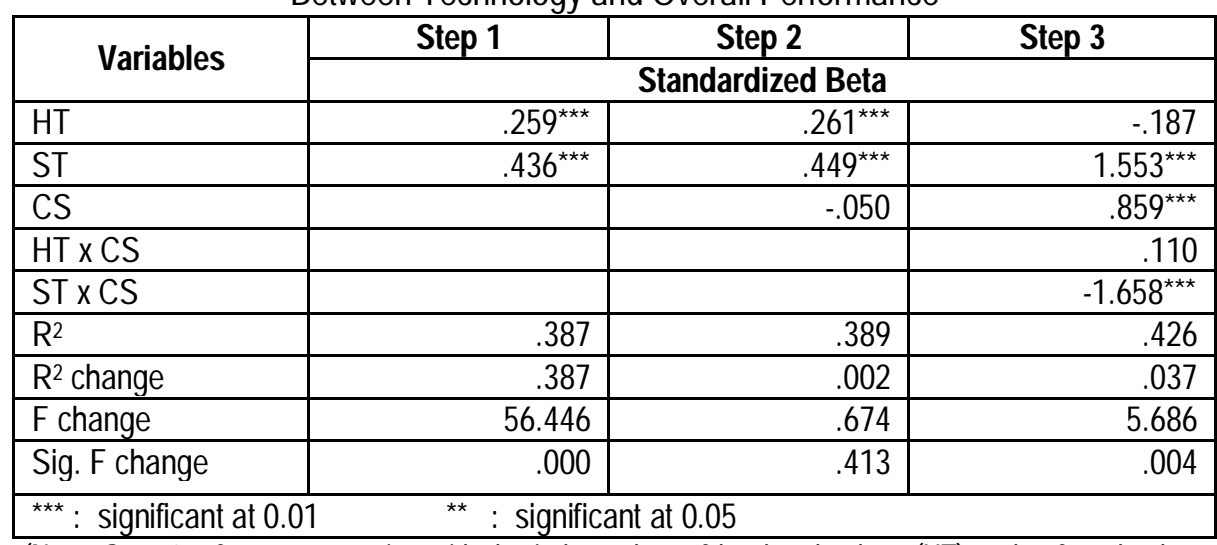

(Note: Step 1 refers to regression with the independent of hard technology (HT) and soft technology (ST); Step 2 refers to regression with the independent variables and the moderator (CS), whilst step 3 refers to the regression with the independent variables, the moderator and the interaction terms)

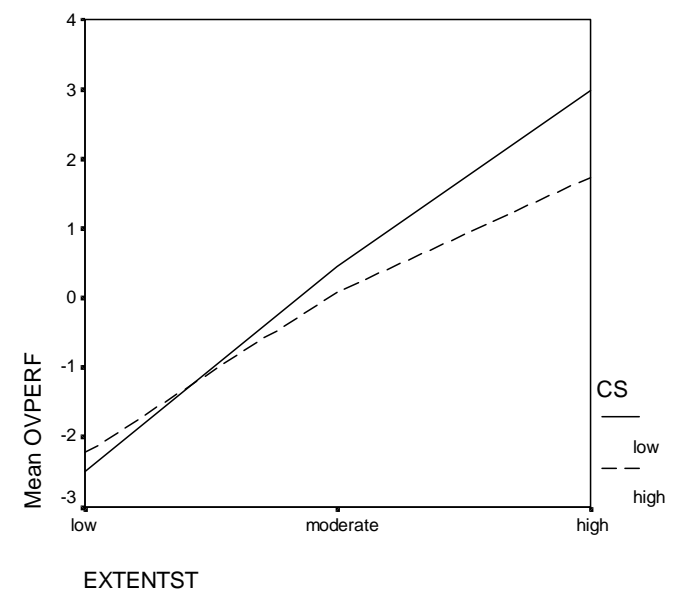

Graph 1: The Impact of Cost Strategy (CS) on the Relationship between Soft Technology (ST) and Overall Performance (OVPERF) 


\section{Quality Strategy as The Moderator}

The moderating impact of quality strategy on the relationship between technology and the overall performance is given in Table 3 . The addition of quality strategy in step 2 does not significantly change the F-ratio and the $\mathrm{R}^{2}$, but the addition of interaction terms in step 3 changes the F-ratio and $\mathrm{R}^{2}$ significantly (Sig. $\mathrm{F}$ change $=$ .67 or sig. at .10). In this case, I find that quality strategy significantly moderates the effect of both hard and soft technology on overall performance.

Table 3: The Moderating Effect of Quality Strategy on The Relationship Between Technology and Overall Performance

\begin{tabular}{|c|c|c|c|}
\hline \multirow{2}{*}{ Variables } & Step 1 & Step 2 & Step 3 \\
\hline & \multicolumn{3}{|c|}{ Standardized Beta } \\
\hline HT & 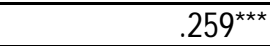 & $.259^{\star \star \star}$ & -.376 \\
\hline ST & 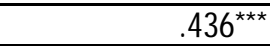 & $.423^{\star \star \star}$ & $1.163^{\star \star \star}$ \\
\hline QS & & .038 & $.500 *$ \\
\hline $\mathrm{HT} \times \mathrm{QS}$ & & & $.794^{\star}$ \\
\hline ST $x$ QS & & & $-1.259 * \star$ \\
\hline $\mathrm{R}^{2}$ & .387 & .388 & .407 \\
\hline $\mathrm{R}^{2}$ change & .387 & .001 & .019 \\
\hline F change & 56.446 & .370 & 2.744 \\
\hline Sig. F change & .000 & .544 & .047 \\
\hline$\star \star \star$ : significant a & ** : signific & nt at 0.05 & ynificant at 0.1 \\
\hline
\end{tabular}

Graph 2 depicts the moderating role of quality strategy on the relationship between hard technology and overall performance. When the level of hard technology is low to moderate, the impact of hard technology on overall performance is positive for those companies that emphasize less quality strategy. Furthermore, when the extent of hard technology is moderate to high, the impact of hard technology on overall performance is positive for those companies with high emphasis on quality strategy, and negative for those companies with low emphasis on quality strategy. The highest performance is achieved when the priority on quality strategy is high while adopting high level of hard technology. It can be argued from perspective that technology allows for greater efficiency and productivity in the operation function, thus improving both manufacturing and financial performance. When coupled with greater focus on quality issues, product produce will be even more competitive and wastages though defects, reworks, and scrap will also be reduced, thus reducing cost of production. This finding corroborates that Butcher et al. (1999), who found that the adoption of AMT (in term of CNC, CAD, LAN, and CIM) and greater emphasis on quality, flexibility and delivery reliability enhances companies' competitiveness through a range of improvement in production processes, quality control, increased capacity, flexibility, improved quality, reduced lead time, and increased internal rate of return. 


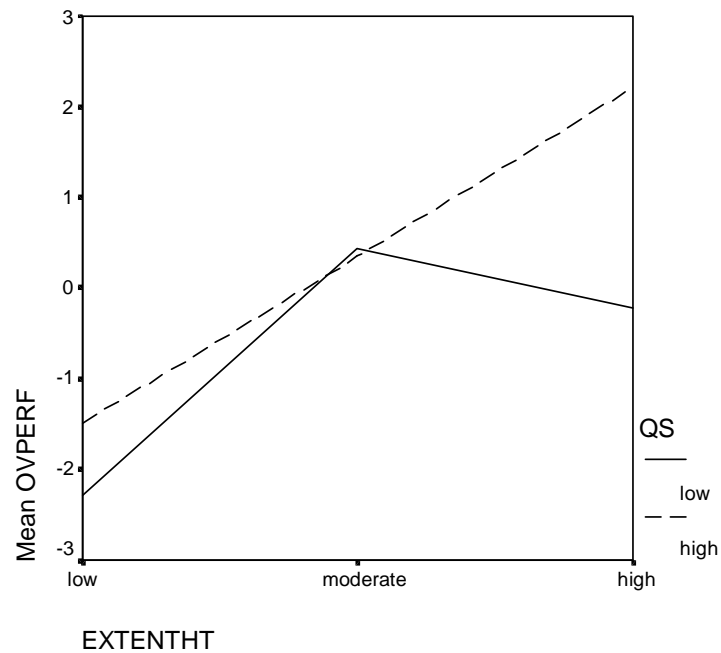

Graph 2: The Impact of Quality Strategy (QS) on the Relationship between Hard Technology (HT) and Overall Performance (OVPERF)

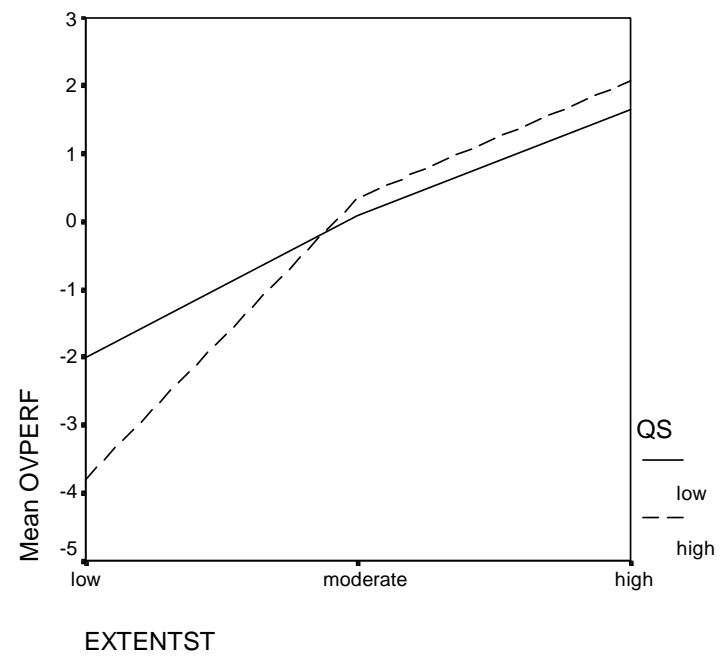

Graph 3: The Impact of Quality Strategy (QS) on the Relationship between Soft technology (ST) and Overall Performance (OVPERF)

The impact of quality strategy on the relationship between soft technology and overall performance is displayed in Graph 3. The distinct in impact of soft technology on overall performance occurs when the level of soft technology is low to moderate, beyond which, the impact is the same. When the extent of soft technology is low to moderate, the impact of soft technology is greater for those companies that 
focus more on quality. The maximum performance is attained if the companies emphasize more on high quality strategy with adopting soft technology in highest level. Since soft technology includes management systems such as TQM, JIT, TPM etc., thus with high level of soft technology would already be emphasizing quality practices. Thus, high or low emphasis on quality strategy will not influence the impact of technology on performance. However, when the level of soft technology adoption is low, focusing on quality strategy will help enhance the impact of technology by raising the performance level. This finding seems contradictory to that of Tan et al. (2000) who argued that companies with greater emphasis on quality strategy and coupled with quality management practices will result in greater impact on performance.

\section{Flexibility Strategy as The Moderator}

The moderating effect of flexibility strategy on the relationship between technology and overall performance is displayed in Table 4. It shows that the Fchange from step 1 to 2 and from step 2 to 3 is significant at $5 \%$ level, respectively. The standardized beta for interaction terms between soft technology and flexibility appears significant at $5 \%$ level.

Table 4: The Moderating Effect of Flexibility Strategy on The Relationship Between Technology and Overall Performance

\begin{tabular}{|c|c|c|c|}
\hline \multirow{2}{*}{ Variables } & Step 1 & Step 2 & Step 3 \\
\hline & \multicolumn{3}{|c|}{ Standardized Beta } \\
\hline HT & $.259^{\star \star \star}$ & $.235^{\star \star \star}$ & -.180 \\
\hline ST & $.436^{\star * *}$ & $.375^{\star \star \star}$ & $1.198^{\star \star \star}$ \\
\hline FS & & $.166^{\star \star}$ & $.843^{\star \star \star}$ \\
\hline HT $\times F S$ & & & .586 \\
\hline ST $x$ FS & & & $-1.501^{\star \star}$ \\
\hline $\mathrm{R}^{2}$ & .387 & 408 & .428 \\
\hline$R^{2}$ change & 387 & .021 & .020 \\
\hline $\mathrm{F}$ change & 56.446 & 6.430 & 3.070 \\
\hline Sig. F change & .000 & .012 & .049 \\
\hline$\overline{\star \star \star}:$ significant $\mathrm{c}$ & significa & at 0.05 & \\
\hline
\end{tabular}

Graph 4 shows that when the extent of soft technology is low to moderate, the impact of soft technology on the overall performance is greater for those companies that put less priority on flexibility strategy. However, when the extent of soft technology is moderate to high, the situation is reverse. Flexibility strategy focuses on meeting the change in customer demand in terms of volume and variety, which typically requires the support from advanced technologies. Thus, having advanced technology without flexibility strategy is a mismatch and this will be reflected in low performance in overall dimensions. This finding was supported by Gerwin (1993), Buthcher et al. (1999) and Beach et al. (2001). 
Graph 4: The Impact of Flexibility Strategy (FS) on the Relationship between Soft Technology (ST) and Overall Performance (OVPERF)

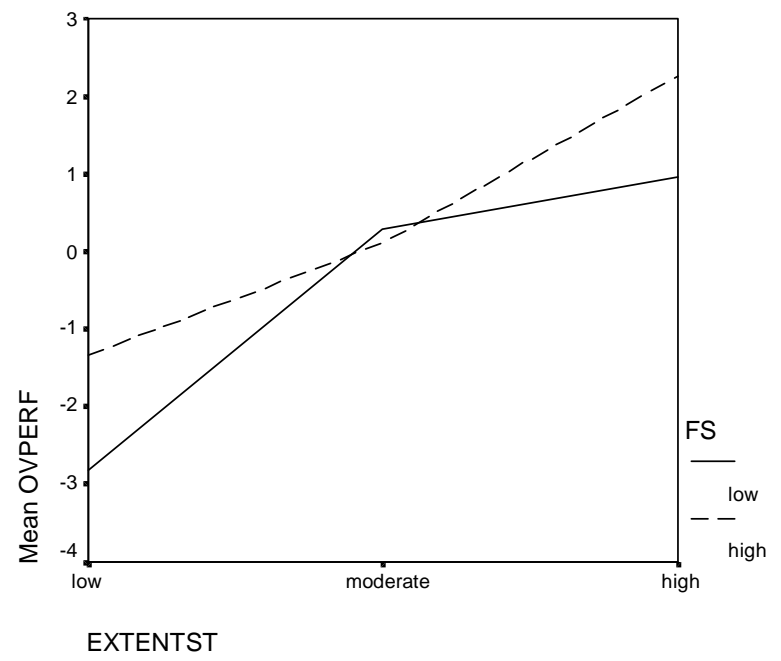

\section{Delivery Strategy as The Moderator}

Table 5 summarizes the results of the regression analysis for testing the moderating role of delivery strategy on the impact of technology on overall performance. This table shows that the addition of delivery strategy in the second step is not significant but the change in F-ratio and $\mathrm{R}^{2}$ is significant with the addition of the interaction terms. The significant beta coefficient for interaction between soft technology and delivery strategy indicates that the relationship between soft technology and the overall performance differs by the level of emphasis on delivery strategy. It is best seen through Graph 4.

Table 5: The Moderating Effect of Delivery Strategy on The Relationship Between Technology and Overall Performance

\begin{tabular}{|c|c|c|c|}
\hline \multirow{2}{*}{ Variables } & Step 1 & Step 2 & Step 3 \\
\hline & \multicolumn{3}{|c|}{ Standardized Beta } \\
\hline HT & $.259 * \star \star$ & $.256^{\star \star \star}$ & -.311 \\
\hline ST & $.436 * \star *$ & $.402^{\star \star \star}$ & $1.287^{\star \star \star}$ \\
\hline DS & & .087 & $.673^{\star \star}$ \\
\hline $\mathrm{HT} \times \mathrm{DS}$ & & & .718 \\
\hline ST $\times$ DS & & & $-1.476^{\star \star \star}$ \\
\hline $\mathrm{R}^{2}$ & .387 & .387 & .393 \\
\hline$R^{2}$ change & .387 & .006 & .024 \\
\hline $\mathrm{F}$ change & 56.446 & 1.819 & 3.661 \\
\hline Sig. F change & .000 & .179 & .028 \\
\hline
\end{tabular}


Graph 5 shows that when the extent of soft technology is low to moderate, the impact of soft technology on overall performance is greater for those companies that emphasize more on delivery strategy. However, in the event when the level soft technology is moderate to high, the situation is reverse. Delivery strategy emphasizes on responding to the customer's order by meeting delivery schedule as well as responding quickly to customer order. Delivery strategy can be operationalized by having soft technologies such as JIT, MRP2 TPM. It is aligning with Schroeder et al (2000) and Cagliano \& Spina (2000) who asserted that through alignment between technology and strategy high pay-off will be achieved.

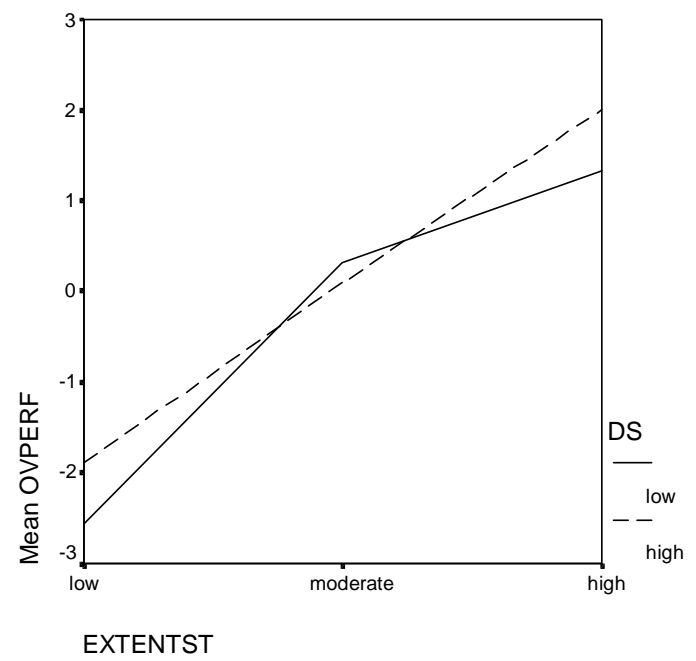

Graph 5: The Impact of Delivery Strategy (DS) on the Relationship between Soft Technology (ST) and Overall Performance (OVPERF)

\section{Moderating Impact of Environmental Hostility}

The last moderating effect that we tested is the moderating effect of environmental hostility on the relationship between technology and overall performance (see Table 6). In this case, the introduction of environmental hostility into the second step is not significant. But the change in F-ratio and $\mathrm{R}^{2}$ is significant with the introduction of the interaction terms. Here we found that both the interaction terms introduced in the step three are significant at $1 \%$ level, indicating that the effects of hard and soft technology on overall performance are moderated by the hostility of environment. 
Table 6: The Moderating Effect of Environmental Hostility Environment Hostility on The Relationship Between Technology and Overall Performance

\begin{tabular}{|c|c|c|c|}
\hline \multirow{2}{*}{ Variables } & Step 1 & Step 2 & Step 3 \\
\hline & \multicolumn{3}{|c|}{ Standardized Beta } \\
\hline HT & $.259 * \star \star$ & $.249^{\star \star \star}$ & $.221^{\star \star \star}$ \\
\hline ST & $.436^{\star \star \star}$ & $.441^{\star \star \star}$ & $.371^{\star \star}$ \\
\hline $\mathrm{EH}$ & & -.025 & -.063 \\
\hline $\mathrm{HT} \times \mathrm{EH}$ & & & $.619^{\star \star \star}$ \\
\hline ST $x$ EH & & & 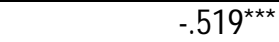 \\
\hline $\mathrm{R}^{2}$ & 387 & 387 & .424 \\
\hline $\mathrm{R}^{2}$ change & .387 & .001 & .036 \\
\hline F change & 56.446 & .156 & 5.526 \\
\hline Sig. F change & .000 & .693 & .005 \\
\hline$\overline{\star \star \star}$ : significant & ** : signific & ant at 0.05 & nnificant at 0.1 \\
\hline
\end{tabular}

Graph 6 shows when the level of hard technology is low to moderate the impact of hard technology on overall performance is greater for companies operating in hostile environment. However, when the level of hard technology is moderate to high, its impact is greater for companies operating in friendly environment. This is supported by the findings of Dean and Snell (1996) who found that in hostile environment, competitors in an industry are more likely to have implemented hard technology, thus limiting the performance impact of technology for any firms.

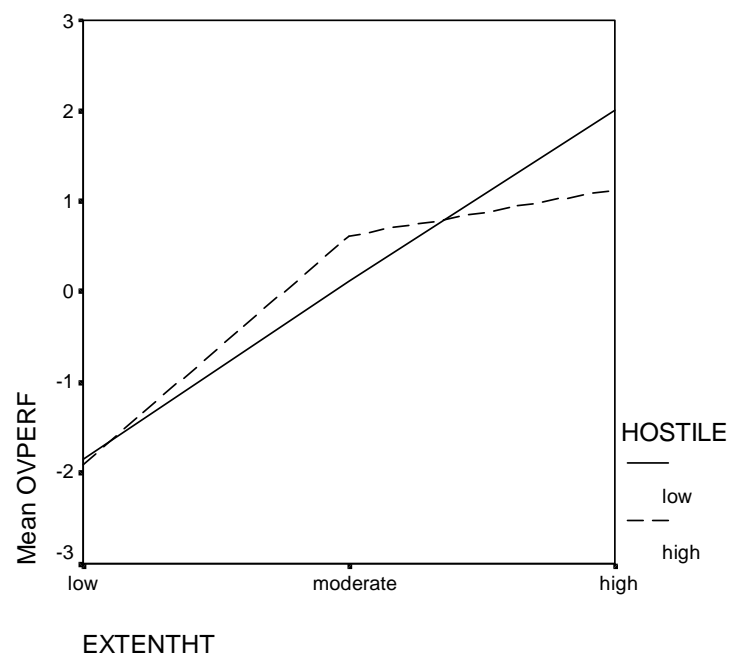

Graph 6: The Impact of Environmental Hostility (EH) on the Relationship between Hard Technology (HT) and Overall Performance (OVPERF) 
Graph 7 illustrates that both in conditions of low and hostile environment the impact of soft technology on the overall performance is always positive. The slopes of the lines indicate that the impact of soft technology on performance is greater in the less hostile environment when the level of soft technology is low to moderate. When level of soft technology is moderate to high, there is no difference in impact. This study also found that environmental hostility moderates the impact of soft technology on financial performance, growth in manufacturing performance and the overall performance. In general, the impact of soft technology on financial performance is greater for those companies operating in less hostile environment. This result reflects that in hostile environment (where the environment is risky), the Indonesian manufacturing companies become cautious, reactive, and risk averse. The pressure does not encourage them to be innovative, and innovation will occur when the environment is friendly and they are under less pressures.

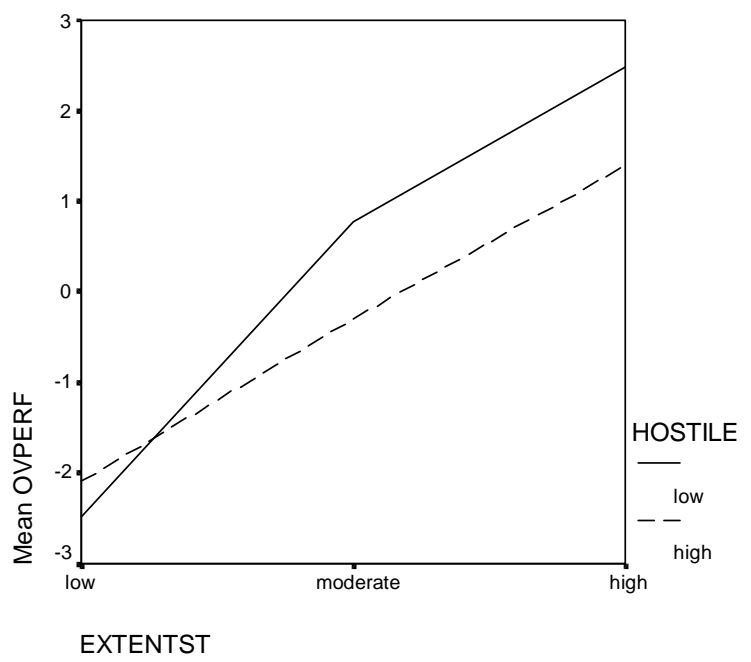

Graph 7: The impact of Environmental Hostility (EH) on the Relationship between Soft Technology (ST) and Overall Performance (OVPERF)

\section{CONCLUSION}

This study provides several implications and directions for future researches. This study suggests that for the Indonesian manufacturing firms to survive and to grow, they need not only to improve its production capacities but also technological capabilities. The process of acquiring the technological capabilities and technological learning is not simple and effortless. Developing and maintaining these capabilities require both conscious efforts by the organizations and also support from other institutions and government, in terms of partnership program and government policy that encourage technological development. 
Indonesian manufacturing firms should consider adopting more of both types of technology. In the real world, the evidence shows that the effective adoption and mastery of technology requires not just the establishment of new production facilities, but also the knowledge and expertise for implementing technical change. The findings of this study also imply that the impact of technology on performance is depended on the manufacturing strategy pursued. Aligning the resources required to support manufacturing strategies in achieving better performance. Further, this study contributes significantly to the understanding of the technology-performance relationship in an environment of developing nations. Indeed, the finding of this study also implies that the impact of technology on performance is depended on the condition of business environment. Our finding indicates that the more hostile the environment, the lower is the impact of technology.

Although this study has presented a systematic approach to investigate the extent of technology adoption, however, it could not cover all the important issues in this field. We recognize that this study has a number of limitations. Data were collected based on perceived, self-judgment, multiple-choice questionnaire. The questionnaires address to CEO (Chief Executive Officer), thus only CEOs responded as their perception of the extent of technological adoption, the environment to be faced and the performance achieved. In this case the potential mono response bias emerges. The nature of requested data in some cases was considered confidential. It could limit their participation in this study. Through this study, we still know little about the relationship between technology and performance. By doing this study it could be possible to observe and document variations of the extent of technological adoption, manufacturing strategy, environment variables and manufacturing performance interrelationship. Although this study used a sample of manufacturing companies in Indonesia, it would be interesting replicate the study on manufacturing companies in other developing countries, which are known to have similar culture in adopting technology. Such a study will address the generalizability of the finding of this study.

\section{REFERENCES}

Abernathy, W.J. \& Clark, K.B. (1985). Innovation mapping the winds of creative destruction, Research Policy, vol. 15. pp. 3.

Al-Hassan, K, Fat-Lam, J, Metcalfe, A. (2000). The role of Total Productive Maintenance in business excellence. Total Quality Management, 11(4), 59-66.

Autioe, A., \& Lemanen, T. (1995). Measurement and evaluation of technology transfer. International Journal of Technology Management, 10, 643-664.

Badri, M.A., Davis, D. \& Davis, D. (2000). Operation strategy, environment uncertainty, and performance: a path analytic model of industries in developing country, Omega, International Journal of Management Science, vol. 28, pp. 155173. 
Barney, J. (1991). Firm's resources and sustained competitive advantage, Journal of Management, 17. pp. 791-800.

Beach, R. Muhlemann, A.P. Price, D.H.R. (2000). Manufacturing operation and strategic flexibility, International Journal of Operation and Production Management, vol. 20(1), pp, 7-30.

Beaumont, N.B. \& Schroeder, R.M. (1997). Technology, Manufacturing Performance, and Business Performance Amongst Australian Manufacturers, Technovation, Vol 17 (6), pp. 297-307.

Braglia, M. \& Petroni, A. (2000). Toward taxonomy of search pattern of manufacturing flexibility in small and medium size firms, Omega, International Journal of Management Science, vol. 28. pp. 195-213.

Buffa, E.S. (1984). Making American manufacturing competitive, California Management Review, 26, Spring, pp. 24-46.

Burgess, T.F. Gules, H.K. Gupta, J.N.D., \& Tekin. (1998). Competitive priorities, process innovations and time based competition in the manufacturing sectors of industrializing economies: the case of Turky, Benchmarking for Quality Management and Technology, vol. 5 (4), pp. 304-316.

Butcher, P., Lee, G., \& Sohal, A. (1999). Lesson for implementing AMT: some case experiences with CNC in Australia, Britain and Canada, International Journal of Production and Operation Management, vol. 19 (5/6), pp. 515-526.

Cagliano, R \& Spina, G. (2000). How improvement programs of manufacturing are selected: the role of strategic priorities and past experience. International Journal of Production and Operation Management, Vol. 20 (7), pp. 772-791.

Dangayah, G.S. \& Deskmukh, S.G. (2000). Manufacturing strategy: experiences from select Indian organizations, Journal Of Manufacturing System, 19 (2), pp 134-148.

Dean, J.W. \& Snell, S.C. (1996). The strategic use integrated manufacturing: an empirical examination. Strategic Management Journal, 17, 459-480.

Gerwin. D. (1993). Manufacturing flexibility, Management Science, vol. 39, pp. 395-410.

Ghobadian, A. \& Galear, D.N. (1996). TQM in SMEs. Omega, International Journal of Management Science. Vol. 24(1). Pp. 83-106.

Gordon, G \& Sohal, A.S. (2001). Assessing manufacturing plant competitiveness: an empirical field study. International Journal of Operation and Production Management, vol. 21(1/2) pp. 233-253. 
Harrison, N \& Samson, D. (1997). International Best Practice in the Adoption and Management of New Technology, Department Industry, Science and Tourism, Australia.

Higgins, J.M. (1995). How effective innovative company operate: lesson from Japan strategy, Creativity and Innovation Management, vol. 4 (2), pp. 110-119.

Hinton, M., Francis, G. \& Holloway J. (2000). Best practice benchmarking in UK, Benchmarking : An International Journal., vol. 7(1), pp. 52-61.

Hottenstein, M.P. \& Dean, J.W. (1992). Managing risk in advanced manufacturing technology, California Management Review, Summer, pp. 112-126.

Humpreys, P., McCurrie, L. \& Mc. Aller, E. (2001). Achieving MRP2 class a status in an SME: a successful case study, Benchmarking: An International Journal, Vol. 8(1), pp. 48-61.

Jantan, M, Ramayah, T, Ismail, N \& Salehudin, A.M. (2001). The COE and AMT adoption in Malaysian small and medium scale manufacturing industries, Proceeding of $10^{\text {th }}$ Conference on Management of Technology, Laussane, Switzerland.

Khalil, T. (2000). Management of Technology: The Key to Competitiveness and Wealt Creation. McGraw-Hill, Singapore.

Kee, T.W. (2000). Implementation Strategies and Implementation Problems, Unpublished MBA Thesis, University Science of Malaysia.

Kotha, S \& Orne, D. (1989). Generic manufacturing Strategies: a conceptual synthesis, Strategic Management Journal, 10, pp. 311-231.

Lindman, F.T., Callarman, T.E., Fowler, K. L., Mc Clatchey, C.A. (2001). Strategic consensus and manufacturing performance, Journal of Managerial Issues, Spring, Vol. XIII no. 1, pp. 45-62.

Lowe, J. \& Sim, A.B. (1993). the diffusion of manufacturing innovation: the case of JIT and MRPII, International Journal of Technology Management, Vol. 8, pp. 244-258.

McGregor, J \& Gomes, C. (1999). Technology Uptake in small and medium-sized enterprises: some evidence from New Zealand, Journal of Small Business, Management, Vol. 37, No 3 pp. 94-103.

Mechling, G.W. Pearce, J.W. \& Busbin, J.W. (1995). Exploiting AMT in small manufacturing firms for global competitiveness, International Journal of Operation and Production Management, no. 2, pp. 61-76.

Miller, D. \& Friesen, P.H. (1983). Strategy-making and environment: the third link, Strategic Management Journal, vol. 4, Pp.221-235. 
Miller, G. (1988). Relating Porter's business strategy to environment and strategy: analysis and implications, Academy Management Journal, 31(2), pp. 280308

Nunnaly, J.C. (1978). Psychometric Theory, $2^{\text {nd }}$ edn. Singapore: Mc Graw Hill.

Porter, M. (1985). Competitive advantage, New York: Free Press.

Price, R.M. (1996). Technology and strategic advantage, California Management Review, vol. 38(3), spring, pp. 38-55.

Sakakibara, S., Flynn, B., Schroeder,R. \& Morriss, W.T. (1997). The impact of JIT manufacturing and infrastructure on manufacturing performance, Management Science, Vol. 43. pp. 1246-1257.

Schroeder, D.M., Congden, S.W. \& Gopinath, C. (1995). Linking competitive strategy and manufacturing process technology, Journal Of Management Studies, 32 (2), pp. 163-189.

Schroeder, D.M. and Congden, S.W. (2000). Aligning competitive strategies, manufacturing technology, and Shop Floor skills, Production and Inventory Management Journal, Fourth Quarter, pp. 40-47.

Seng, O.Y. (2002). Implementing Total Productive Maintenance (TPM) In An Industrial Manufacturing Organization: An Operational Strategy Study, MA Thesis, University Science of Malaysia.

Shariff, M.M. (1997). Technology strategy in developing countries: evolving from comparative to competitive advantage, International Journal Of Technology Management, Vol. 14, Nos. 2/3/4, pp. 309-343.

Skinner, W. (1974), The focused factory, Harvard Business Review, no. 52(3), pp. 495-504.

Skinner, W. (1985). Operation technology, Interfaces, 14 (1), pp. 116-125.

Sohal, A.S. Butcher, P.G., Millen, R. \& Lee, G. (1999). Comparing American and British practices in AMT adoption, Benchmarking: An International Journal, vol. 6 (4), pp. 310-324.

Sohal, A.S. \& Terziovsky, M. (2000). TQM in Australian manufacturing: factor critical to success, International Journal of Quality and Reliability Management, vol. 17 (2). Pp. 158-167.

Stonebaker, P. \& Leong, G. (1994). Operation Strategy: Focusing Competitive Excellence, Boston, MA, Allyn and Bacon.

Swamidas, P. \& Newell, P. (1987). Manufacturing strategy, environmental uncertainty: a path analytical model, Management Science, Vol. 33(40, pp. 509-524. 
Sweene, M.T. (1991). Toward unified theory of strategic management, International Journal of Production and Operation Management, 11 (8), pp. 6-22.

Tan, K.C., Kannan, V.R., Handfield, R.B., \& Ghosh, S. (2000). Qualiy, manufacturing Strategy, and Global Competition: An Empirical Annalysis, Benchmarking: An International Journal, vol. 7(3), pp. 174-182.

Tsang, A.J.H., \& Chan, P.K. (2000). TPM implementation in China a case study, International Journal of Quality and Reliability Management, Vol. 17(2), pp. 144-157.

Warnock, I. (1996). Manufacturing and Business Excellence: Strategies, Techniques, and Technologies. Prentice Hall Europe.

Wheelwright, S.C. \& Hayes, R.H. (1985). Competing through Manufacturing, Harvard Business Review, January-February, pp. 99-109.

Yamashima, H. (2000). Challenge to world class manufacturing, International Journal of Quality and Reliability Management, Vol. 17(2), pp. 132-143.

Yasin, M.M., Small, M., \& Wafa, M.A. (1997). An empirical investigation of JIT effectiveness: an organizational perspective, Omega, International Journal of Management Science, vol. 25 pp. 461-471.

Youseff, M.A. (1993). Computer based technology and their impact on manufacturing flexibility, International Journal of Technology Management, Vol. 8. pp. 355370.

Zeleny, M. (1986). High technology Management. Human Systems Management, 6, 169-120.

Zairi, M. \& Whymark, J. (2000). The transfer of best practices: how to build a culture of benchmarking and continuous learning, Benchmarking: An International Journal, Vol. 7(1), pp. 62-78.

Zahra, S.J. and Covin J.G. (1993). Business Strategy, technology policy, and firms performance, Strategic Management Journal, 14 pp. 451-478.

Zammuto, R.F. \& O'Connor, K. (1992). Gaining advanced manufacturing technologies benefit: the role of organization design and culture, Academy Management Review, vol. 17(4). Pp. 701. 